\title{
Securitization and Optimal Retention under Moral Hazard
}

\author{
Sara Malekan and Georges Dionne \\ Canada Research Chair in Risk Management, HEC Montréal
}

May 2012

\begin{abstract}
Securitization is one of the most important innovations in financial markets. It is a process of converting illiquid loans that cannot be sold readily to third-party investors into liquid securities and selling them to dispersed investors. As a result, securitization improves liquidity in capital markets by allowing originators to remove the issued loans from its balance sheet and use the proceeds for other purposes or even to originate new loans. In spite of all its advantages, securitization is often suspected of being one of the main reasons for the recent financial crisis. One concern that is frequently raised in the literature is that securitization leads to moral hazard in lender screening and monitoring. By selling loans to investors and removing them from their books, banks have a lesser incentive to carefully evaluate and monitor borrowers' credit quality to ensure that they can repay the loans, because the risk of delinquencies falls on investors rather than lenders. One problem in the literature is that the analysis of securitization is very general and suffers from a lack a specific security design analysis under asymmetric information. We address the moral hazard problem using a principal-agent model where the investor is the principal and the lender is the agent. We show that the optimal contract must contain a retention clause in the presence of moral hazard.
\end{abstract}

Keywords: Securitization, optimal retention, moral hazard, principal-agent model, default, screening, monitoring. JEL codes: D81, D82, D86, G24.

\section{Introduction}

Securitization is one of the most important innovations in financial markets. It is the process of pooling financial assets such as debt instruments and individual loans and then packaging and converting them into securities and selling them in the form of tranches (prioritized capital structure of claims) or other credit enhancement to thirdparty investors (Kendall and Fishman, 2000). In other words, securitization is a process of converting illiquid loans that cannot be sold readily to third-party investors into liquid securities and selling them to dispersed investors. As a result, securitization improves liquidity in capital markets by allowing originators to remove the issued loans from their balance sheet and use the proceeds for other purposes or even to originate new loans (Coval, Jurek, and Stafford, 2009; Demarzo, 2005). Because of the attractiveness of securitization for financial market participants, its application has widely been extended in recent years. In April 2011, the volume of outstanding securitized assets reached $\$ 11$ trillion, which is substantially greater than the overall outstanding marketable US Treasury securities of $\$ 8$ trillion (US Department of the Treasury, 2011). 
In spite of all its advantages, securitization is often suspected of being one of the main reasons for the recent financial crisis. One concern that is frequently raised in the literature is that securitization leads to moral hazard in lender screening and monitoring (Gorton and Pennacchi, 1995; Parlour and Plantin, 2008; Berndt and Gupta, 2009; Brunnermeier, 2009; Mian and Sufi, 2009; Selody and Woodman, 2009; Fender and Mitchell, 2009a; Rajan, 2010; Donnelly and Embrechts, 2010; Keys, Mukherjee, Seru and Vig 2010; 2011). By selling loans to investors and removing them from their books, banks have a lesser incentive to carefully evaluate and monitor borrowers' credit quality to ensure that they can repay the loans, because the risk of delinquencies falls on investors rather than lenders. Securitization changes screening and monitoring behavior and raises information asymmetry between lenders and investors. The resulting information asymmetry may be costly to the investors, because of the distance between borrowers and investors. The benefits of securitization are thus limited by information asymmetry between lenders and investors and in particular by the costs of this non-transparency. It is becoming important for regulators and market participants to understand the costs and benefits of securitization so that they can appropriately improve the incentives and scope of securitization to mitigate this information cost.

Tranche retention seems to be a wise solution to solve the moral hazard problem of securitization. It is now used frequently by the International Organization of Securities Commissions (IOSCO, 2009; US Treasury, 2009; European Parliament, 2009) to revitalize securitization markets. To maintain incentives to screen and monitor loans, it seems logical to require lenders to retain part of securitized loans so that they remain exposed to the risk. One problem is that the analysis of securitization is very general and suffers from a lack of specific security design analysis under asymmetric information. In other words, there is not yet in the literature an optimal model that endogenously specifies the exact form and amount of optimal retention to keep the lender's incentive at the optimal level.

We are among the first to investigate the optimal security design of structured products under moral hazard. Our goal is to address the moral hazard problem using a principal-agent model where the investor is the principal and the lender is the agent. Without securitization, all the costs and benefits of screening and monitoring are internal to the lender and incentive to screen and monitor is optimal. With securitization, originators sell part of their risk to a third party, and do not bear the full cost of loan default. The more the investors contribute to covering the default cost, the less incentive lenders have to carefully screen and monitor borrowers. In Section 2, we propose our principal-agent model and in Section 3 we show how to mitigate moral hazard in screening and monitoring by specifying the optimal amount of the loan pool that lenders should hold to maintain their incentive under ex ante moral hazard. Section 4 concludes the analysis. 


\section{The model}

We consider a risk-averse originator or bank that detains a loan pool with a value normalized to 1 . The loan pool is assumed to be large enough to diversify away the idiosyncratic risk. The originator could keep these loans in the balance sheet or securitize them to risk-neutral and competitive investors. The risk-free rate of interest is normalized to zero. We assume that the average default probability of loan pool is $p(e)$, which is a function of the screening and monitoring effort $e \in[0, \bar{e}]$. Effort $e$ could be undertaken by lenders to decrease the probability of loan default. We assume $p(e)$ is decreasing and convex in effort:

$p^{\prime}(e)<0, p^{\prime \prime}(e)>0, p(0)<1$ and $p(\bar{e})>0$.

Effort is costly for originators. The cost function is equal to $C(e)$ and is increasing and convex in $e$ :

$C(0)=0, C^{\prime}(e)>0, C^{\prime \prime}(e)>0$.

In the case of loan default there is a random conditional loss $L$, which is in the interval $[0,1]: 0 \leq L \leq 1$, with distribution function $F(L)$ and density function $f(L) . F$ is the distribution of loss, conditional on default. In this article we assume that effort decreases the probability of default without changing the conditional distribution $F(L)$.

We assume that there is only one tranche and there is no credit enhancement procedure in the securitization. In this case the special purpose vehicle issues financial assets that are not prioritized and are simply fractional claims to the payoff on the underlying portfolio. Because the expected portfolio loss is equal to the mean expected loss on the underlying securities, the average portfolio's credit rating is given by the average rating of the securities in the underlying pool (Coval, Jurek, and Stafford, 2009).

The rate of return on the loan pool is $R$, which is assumed positive: $R>0$. In the presence of securitization, we assume that the originator can securitize part of the loan pool and keep a fraction $\alpha$ of the loans (retention). We also assume that the originator's decision to securitize or not is made at the same time as loan origination. After securitization, originators can choose their monitoring effort level. Monitoring effort cannot be observed by investors. Another interpretation would be that the average risk is evaluated by a rating agency that does not observe effort. Therefore, it cannot be contractible. Our objective is to find the optimal $\alpha$.

Securitization generates liquidity for the originator prior to the loan's maturity. As mentioned previously, we assume that third-party investors are competitive. Thus the amount they are willing to pay is equal to the expected value of their payoff from the securitized loans. If the originator securitizes the entire loan pool, it will receive a return equal to $1+S . S$ is the rate of return on the loan pool that takes into account the potential default risk of the 
loan pool. Therefore $S$ is smaller than or equal to $R$. The difference between $R$ and $S$ is considered as the sum of transferred expected loss to investors plus the risk premium. The risk premium is the maximum amount that a risk-averse originator is willing to pay above the transferred expected loss to eliminate the default risk of the loan pool by transferring it to the market. If the originator keeps a $\alpha$ fraction of the loan pool, it will receive $(1-\alpha)(1+S)$ from securitization.

\section{Investors' objective function}

The objective of the model is to maximize the expected return of the investors under different constraints. In the non-default state the investors' return is equal to $(1-\alpha)(1+R)$, because they have only $(1-\alpha)$ fraction of the entire loan pool. If the loan pool defaults, the $\alpha$ fraction kept by the originator absorbs initial losses until it is completely exhausted. Therefore, if the loss amount is small enough that it does not consume the entire $\alpha$ fraction, the investor loses nothing. If the amount of loss is large enough to exhaust the $\alpha$ fraction, investors' expected loss is equal to $\int_{\alpha}^{1}(L-\alpha)(1+R) f(L) d L$. The investors' objective function is then equal to:

$\pi_{I} \equiv(1-\alpha)(R-S)-p(e) \int_{\alpha}^{1}(L-\alpha)(1+R) f(L) d L$.

With full securitization, when $\alpha=0$, the investors' objective function is reduced to:

$\pi_{I} \equiv(R-S)-p(e) \int_{0}^{1} L(1+R) f(L) d L$.

We are looking for the optimal retention in the case of securitization that will keep the originator's incentive at the most favorable level. First we assume that there is no securitization and calculate the originator's first best effort . Then we assume that there is securitization, while effort is observable and there is no moral hazard. In this case, given the first best effort level, we determine the optimal amount of retention. Finally we investigate the optimal amount of retention with moral hazard. We must consider three kinds of constraints in this model:

- participation constraint

- incentive compatibility constraint

- technology constraint

\section{- Participation constraint}

The originator's welfare in the case of securitization should be greater than or equal to its welfare in the case of no securitization. We assume the originator is risk averse, so its marginal utility of wealth is decreasing in wealth: $U^{\prime}(w)>0, U^{\prime \prime}(w)<0$, where $w$ is final wealth. This assumption is not critical to the result regarding the optimal form of contract : we obtain similar results when investors are risk averse or in a limited liability framework. 
In the absence of securitization, the originator holds the entire loan pool on its balance sheet and screens and monitors the loans cautiously. In this case the originator's payoff when there is no default will be $U(R)$, and if there is default, it will be $\int_{0}^{1} U(R-L(1+R)) f(L) d L$. Its expected utility is given by:

$\pi_{O}=[1-p(e)] U(R)+p(e) \int_{0}^{1} U(R-L(1+R)) f(L) d L-C(e)$.

From the first-order condition with respect to $e$, we calculate the first best effort that the originator can put forth to maximize its expected utility in the absence of securitization. This condition is equal to:

$C^{\prime}(e)=p^{\prime}(e)\left[\int_{0}^{1} U(R-L(1+R)) f(L) d L-U(R)\right]$.

The solution is $e^{* *}$. The second-order condition is negative at the optimum. Details are in Appendix (A.1). Without securitization, the originator exerts the first best effort to maximize the expected utility that can be calculated by inserting the first best effort level in the originator's expected utility as follows:

$\left[1-p\left(e^{* *}\right)\right] U(R)+p\left(e^{* *}\right) \int_{0}^{1} U(R-L(1+R)) f(L) d L-C\left(e^{* *}\right)=\bar{U}$.

$\bar{U}$ is the best opportunity when considering securitization. To satisfy the participation constraint, the originator's expected utility in the presence of securitization should be at least equal to $\bar{U}$.

In the case of securitization, we can write the originator's expected utility as follows:

$(1-p(e)) U(R-(1-\alpha)(R-S))+$

$p(e)\left[\int_{0}^{\alpha} U(R-(1-\alpha)(R-S)-L(1+R)) f(L) d L+\int_{\alpha}^{1} U(R-(1-\alpha)(R-S)-\alpha(1+R)) f(L) d L\right]-C(e)$.

$R-(1-\alpha)(R-S)$ is the originator's payoff in the state of non-default. The expected return on the entire loan pool is $(1+R)$, but because the originator keeps only the $\alpha$ fraction of the loan pool, it will receive the $\alpha$ fraction of the return: $\alpha(1+R)$. For the rest of the loan pool, the originator will receive: $(1-\alpha)(1+S)$ from securitization. Summing up these returns yields the payoff: $R-(1-\alpha)(R-S)$.

In the case of default, because the $\alpha$ fraction is exhausted first, the expected utility is equal to:

$\int_{0}^{\alpha} U(R-(1-\alpha)(R-S)-L(1+R)) f(L) d L+\int_{\alpha}^{1} U(R-(1-\alpha)(R-S)-\alpha(1+R)) f(L) d L$.

If the loss amount is less than $\alpha$, the originator loses: $L(1+R)$. When the loss amount is greater than $\alpha$, the originator loses $\alpha(1+R)$. The probability of the first alternative is equal to: $F(\alpha)=1-\int_{\alpha}^{1} f(L) d L$. 
To obtain the participation constraint, we equate the expected utility in the case of securitization to the expected utility in the case of no securitization while exerting the first best effort. We assume that this constraint is binding. We assign $\lambda$ as the Lagrange multiplier to the originator's participation constraint:

$(1-p(e)) U(R-(1-\alpha)(R-S))+$

$p(e)\left[\int_{0}^{\alpha} U(R-(1-\alpha)(R-S)-L(1+R)) f(L) d L+\int_{\alpha}^{1} U(R-(1-\alpha)(R-S)-\alpha(1+R)) f(L) d L\right]-C(e)=\bar{U}$.

The left-hand side of this constraint must be evaluated at the optimal effort under securitization. We must now compute the optimal effort by analyzing the incentive compatibility constraint under securitization.

\section{- Incentive compatibility constraint:}

This constraint ensures the effectiveness of the originator's screening and monitoring effort under moral hazard. By differentiating the originator's expected utility in the presence of securitization with respect to screening and monitoring effort (first-order condition for choice of effort), we can obtain the incentive compatibility constraint as follows:

$$
p^{\prime}\left(e^{*}\right)\left[\begin{array}{l}
\int_{0}^{\alpha} U(R-(1-\alpha)(R-S)-L(1+R)) f(L) d L+\int_{\alpha}^{1} U(R-(1-\alpha)(R-S)-\alpha(1+R)) f(L) d L \\
-U(R-(1-\alpha)(R-S))
\end{array}\right]-C^{\prime}\left(e^{*}\right)=0 .
$$

We assign $\mu$ as a Lagrange multiplier of this constraint. When $\alpha=0$ (full securitization), the marginal benefit of effort is equal to zero:

$$
p^{\prime}(e)\left[\begin{array}{l}
\int_{0}^{\alpha} U(R-(1-\alpha)(R-S)-L(1+R)) f(L) d L+\int_{\alpha}^{1} U(R-(1-\alpha)(R-S)-\alpha(1+R)) f(L) d L \\
-U(R-(1-\alpha)(R-S))
\end{array}\right]=0
$$

Because the marginal cost $C^{\prime}\left(e^{*}\right)$ is positive, the first-order condition is strictly negative; as a result $e^{*}$ is equal to zero.

\section{- Technology constraint:}

This constraint can be applied to ensure that there is no oversecuritization. It excludes $\alpha>1 . \delta \geq 0$ is the multiplier of this constraint.

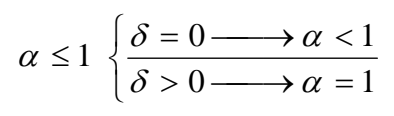




\section{Optimal securitization}

Optimal securitization solves the following principal-agent program:

$\operatorname{Max}_{\alpha, S, e} \pi_{1}=(1-\alpha)(R-S)-p(e) \int_{\alpha}^{1}(L-\alpha) f(L) d L(1+R)$

$\mu: p^{\prime}(e)\left[\begin{array}{l}\int_{0}^{\alpha} U(R-(1-\alpha)(R-S)-L(1+R)) f(L) d L+\int_{\alpha}^{1} U(R-(1-\alpha)(R-S)-\alpha(1+R)) f(L) d L \\ -U(R-(1-\alpha)(R-S))\end{array}\right]-C^{\prime}(e)=0$

$\lambda:(1-p(e)) U(R-(1-\alpha)(R-S))+$

$p(e)\left[\int_{0}^{\alpha} U(R-(1-\alpha)(R-S)-L(1+R)) f(L) d L+\int_{\alpha}^{1} U(R-(1-\alpha)(R-S)-\alpha(1+R)) f(L) d L\right]-C(e)=\bar{U}$

$\delta: \alpha \leq 1$

- $\quad$ No Moral Hazard: $\mu=0$

First we assume that $\mu=0$ when there is no moral hazard and $e=e^{* *}$. The investor checks $e$ and sets its level at $e^{* *}$ by using the "take it or leave it" strategy. If we differentiate (14) with respect to $S$, we have:

$S:-(1-\alpha)+\lambda(1-p(e)) U^{\prime}(R-(1-\alpha)(R-S))(1-\alpha)+$

$\lambda p(e)\left[\int_{0}^{\alpha} U^{\prime}(R-(1-\alpha)(R-S)-L(1+R))(1-\alpha) f(L) d L+\int_{\alpha}^{1} U^{\prime}(R-(1-\alpha)(R-S)-\alpha(1+R))(1-\alpha) f(L) d L\right]=0$.

By solving the above equation, we can isolate $1 / \lambda$ as follows:

$\frac{1}{\lambda}=(1-p(e)) U^{\prime}(R-(1-\alpha)(R-S))+$

$p(e)\left[\int_{0}^{\alpha} U^{\prime}(R-(1-\alpha)(R-S)-L(1+R)) f(L) d L+\int_{\alpha}^{1} U^{\prime}(R-(1-\alpha)(R-S)-\alpha(1+R)) f(L) d L\right]$.

Differentiating (14) with respect to $\alpha$ yields:

$(R-S)-p(e)(1-F(\alpha))(1+R)=\lambda(1-p(e)) U^{\prime}(R-(1-\alpha)(R-S))(R-S)$

$+\lambda p(e) \int_{0}^{\alpha} U^{\prime}(R-(1-\alpha)(R-S)-L(1+R))(R-S) f(L) d L-\lambda p(e) U^{\prime}(R-(1-\alpha)(R-S)-\alpha(1+R))(1+S)(1-F(\alpha))$.

By solving this equation for $1 / \lambda$, we obtain: 


$$
\frac{1}{\lambda}=\left\{\begin{array}{l}
\frac{(1-p(e)) U^{\prime}(R-(1-\alpha)(R-S))(R-S)}{(R-S)-p(e)(1-F(\alpha))(1+R)}+ \\
\frac{p(e) \int_{0}^{\alpha} U^{\prime}(R-(1-\alpha)(R-S)-L(1+R))(R-S) f(L) d L}{(R-S)-p(e)(1-F(\alpha))(1+R)}-\frac{p(e) U^{\prime}(R-(1-\alpha)(R-S)-\alpha(1+R))(1+S)(1-F(\alpha))}{(R-S)-p(e)(1-F(\alpha))(1+R)}
\end{array}\right\}
$$

By equalizing the two equations (16) and (18) together we get the following result:

$$
\begin{aligned}
& U^{\prime}(R-(1-\alpha)(R-S)-\alpha(1+R))=(1-p(e)) U^{\prime}(R-(1-\alpha)(R-S))+ \\
& p(e) \int_{0}^{\alpha} U^{\prime}(R-(1-\alpha)(R-S)-L(1+R)) f(L) d L+p(e)(1-F(\alpha)) U^{\prime}(R-(1-\alpha)(R-S)-\alpha(1+R))
\end{aligned}
$$

$\alpha=0$ solves this equation. We can also verify that $\mathrm{R}>\mathrm{S}$ at the optimum. From the participation constraint we have the following relationship:

$$
U(S)-C\left(e^{* *}\right)=\left(\left(1-p\left(e^{* *}\right)\right) U(R)+p\left(e^{* *}\right)\left[\int_{0}^{1} U(R-L(1+R)) f(L) d L\right]-C\left(e^{* *}\right) .\right.
$$

By applying Taylor expansion to both side of equation (20), we obtain the expected loss and the risk premium:

$$
S=R-p\left(e^{* *}\right)(1+R)\left[\int_{0}^{1} L f(L) d L\right]+\frac{1}{2} p(e) \frac{U^{\prime \prime}(R)}{U^{\prime}(R)} \int{ }_{0}^{1} L^{2}(1+R)^{2} f(L) d L
$$

Details are in Appendix (A.2).

Because the risk premium is positive, we can verify that:

$$
(R-S)>p\left(e^{* *}\right)(1+R)\left[\int_{0}^{1} L f(L) d L\right]
$$

The investor uses its power to extract the risk premium from the risk-averse bank. Under risk neutrality, $(R-S)$ is equal to expected loss.

\section{- $\quad$ Moral Hazard : $\mu \neq 0$}

Now we assume that $\mu \neq 0$ because there is potential moral hazard. Differentiating (14) with respect to $S$, we obtain after simplification:

$$
\begin{aligned}
& \frac{1-\lambda U^{\prime}(R-(1-\alpha)(R-S))}{\lambda p(e)+\mu p^{\prime}(e)}= \\
& {\left[\begin{array}{l}
-U^{\prime}(R-(1-\alpha)(R-S)) \\
+\int_{0}^{\alpha} U^{\prime}(R-(1-\alpha)(R-S)-L(1+R)) f(L) d L+U^{\prime}(R-(1-\alpha)(R-S)-\alpha(1+R))(1-F(\alpha))
\end{array}\right]}
\end{aligned}
$$

Differentiating (14) with respect to $\alpha$ yields, after simplification: 


$$
\begin{aligned}
& (R-S)-p(e)(1-F(\alpha))(1+R)=\lambda U^{\prime}(R-(1-\alpha)(R-S))(R-S)+ \\
& \left(\lambda p(e)+\mu p^{\prime}(e)\right)\left[\begin{array}{l}
-U^{\prime}(R-(1-\alpha)(R-S))(R-S)-(1-F(\alpha)) U^{\prime}(R-(1-\alpha)(R-S)-\alpha(1+R))(1+S) \\
+\int_{0}^{\alpha} U^{\prime}(R-(1-\alpha)(R-S)-L(1+R))(R-S) f(L) d L
\end{array}\right]
\end{aligned}
$$

The two first-order conditions can be rewritten as:

$$
\begin{aligned}
& U^{\prime}(R-(1-\alpha)(R-S)-\alpha(1+R))=\left(\lambda U^{\prime}(3)-p(e)\right)\left[U^{\prime}(R-(1-\alpha)(R-S))\right]+ \\
& p(e) \int_{0}^{\alpha} U^{\prime}(R-(1-\alpha)(R-S)-L(1+R)) f(L) d L+p(e)(1-F(\alpha)) U^{\prime}(R-(1-\alpha)(R-S)-\alpha(1+R))
\end{aligned}
$$

Where $U^{\prime}(R-(1-\alpha)(R-S)-\alpha(1+R))=U^{\prime}(3)$

We analyze two cases. First consider $\lambda<\frac{1}{U^{\prime}(3)}$ :

$U^{\prime}(R-(1-\alpha)(R-S)-\alpha(1+R))<(1-p(e))\left[U^{\prime}(R-(1-\alpha)(R-S))\right]+$

$$
p(e) \int_{0}^{\alpha} U^{\prime}(R-(1-\alpha)(R-S)-L(1+R)) f(L) d L+p(e)(1-F(\alpha)) U^{\prime}(R-(1-\alpha)(R-S)-\alpha(1+R))
$$

Because $U^{\prime}$ is decreasing in wealth, this means that $\alpha$ should be smaller than or equal to zero to solve (25). Because $\alpha$ cannot be smaller than zero, this means that there should be full securitization. By putting $\alpha=0$ in the above equation we get the following result:

$U^{\prime}(S)<(1-p(e))\left[U^{\prime}(S)\right]+p(e)(1-F(\alpha)) U^{\prime}(S)=U^{\prime}(S)$

which is a contradiction because $F(0)=0$ and we reject this possibility.

Now considering $\lambda>\frac{1}{U^{\prime}(3)}$, we obtain:

$U^{\prime}(R-(1-\alpha)(R-S)-\alpha(1+R))>(1-p(e))\left[U^{\prime}(R-(1-\alpha)(R-S))\right]+$

$p(e) \int_{0}^{\alpha} U^{\prime}(R-(1-\alpha)(R-S)-L(1+R)) f(L) d L+p(e)(1-F(\alpha)) U^{\prime}(R-(1-\alpha)(R-S)-\alpha(1+R))$

Because $U^{\prime}$ is decreasing in wealth, this means that $\alpha$ should be greater than zero to solve this inequality. This implies that full securitization is not optimal and there must be retention under moral hazard. The optimal solution, $\alpha^{*}>0$, means that:

$L-$ Investor loss $=\alpha^{*}>0$, when investor loss is greater than zero, which means $\alpha^{*}<1$. Therefore: Investor loss $=L-\alpha^{*} \geq 0$; If $L<\alpha^{*}$ : Investor loss $=0$; If $L \geq \alpha^{*}$ : Investor loss $=L-\alpha^{*}$. Finally, we obtain that full retention can also be an optimal solution. 
Based on the above result, we can show the relationship between investor and portfolio loss in the following figure:

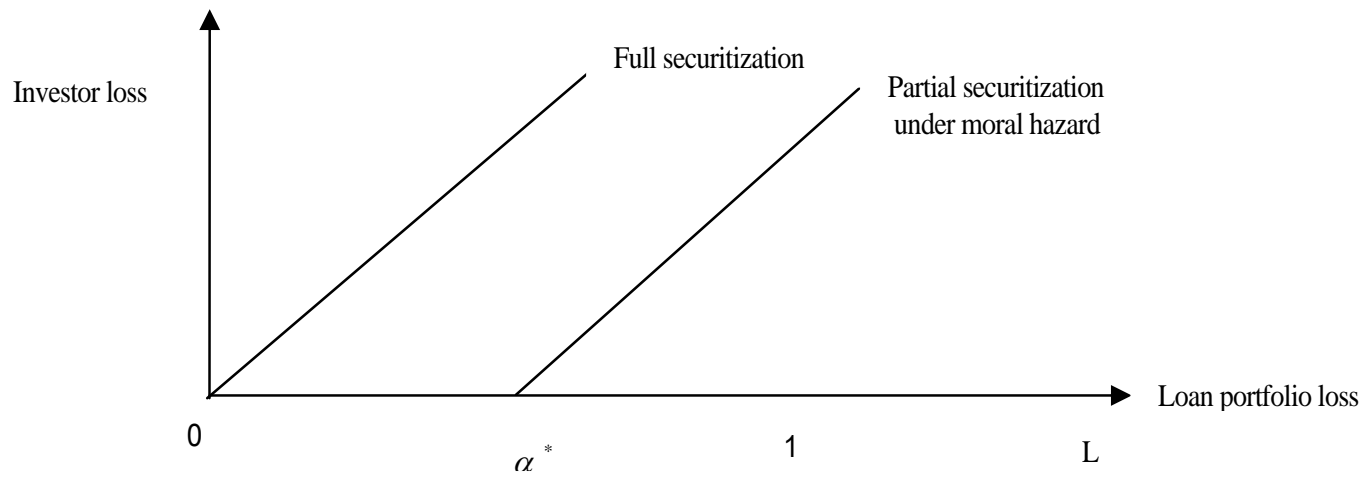

Figure 1

Investor loss equals 0 when $L<\alpha^{*}$ and equals $L-\alpha^{*}$ when $L \geq \alpha^{*}$.

\section{Conclusion}

In this paper, we applied the security design methodology to securitization to obtain the optimal risk sharing between sellers and buyers of these products. To the best of our knowledge, this article is the first to analyze the incentive contracting of securitized products under moral hazard. We prove that the optimal contract must contain a partial retention clause in the presence of moral hazard. The optimal amount of retention could then be calculated using our model with different parameter values. We can take one step further by considering structured asset-backed securitization with both the absence and the presence of the correlation between assets in the original pool. These correlations were not considered before the recent financial crisis, which led to underestimation of true default probabilities of tranches in the presence of systemic risk. This also resulted in the inaccurate rating of the financial products associated with different tranches. 


\section{Appendix A}

\section{A.1 Second-order condition}

The second-order condition is negative at the optimum: $C^{\prime \prime}(e)>0, p^{\prime \prime}(e)>0$ and $R-L(1+R)<R$ implies that $\int_{0}^{1} U(R-L(1+R)) f(L) d L-U(R)$ is negative. As a result we verify the negativity of the S.O.C:

$-C^{\prime \prime}\left(e^{* *}\right)+p^{\prime \prime}\left(e^{* *}\right)\left[\int_{0}^{1} U(R-L(1+R)) f(L) d L-U(R)\right]<0$

\section{A.2 Risk premium when there is no moral hazard}

We can verify that $R>S$ and by calculating the difference between $R$ and $S$ we can calculate the risk premium. From the participation constraint we have the following:

$$
\begin{aligned}
& \bar{U}=(1-p(e)) U(R-(1-\alpha)(R-S))+ \\
& p(e)\left[\int_{0}^{\alpha} U(R-(1-\alpha)(R-S)-L(1+R)) f(L) d L+\int_{\alpha}^{1} U(R-(1-\alpha)(R-S)-\alpha(1+R)) f(L) d L\right]-C(e)
\end{aligned}
$$

When there is no securitization ( $\alpha=0$ ), the originator will exert the first best effort level $e^{* *}$, and the right-hand side of the above equation is equal to:

$U(S)-C\left(e^{* *}\right)$

The originator's expected utility without securitization while the originator exerts the first best effort is equal to:

$\left(1-p\left(e^{* *}\right)\right) U(R)+p\left(e^{* *}\right) \int_{0}^{1} U(R-L(1+R)) f(L) d L-C\left(e^{* *}\right)$

Equalizing these two equations yields the following equality from the participation constraint:

$U(S)-C\left(e^{* *}\right)=\left(1-p\left(e^{* *}\right)\right) U(R)+p\left(e^{* *}\right) \int_{0}^{1} U(R-L(1+R)) f(L) d L-C\left(e^{* *}\right)$

We can calculate the risk premium by applying a Taylor expansion around $\mathrm{R}$ to both sides of equation (A.5). The Taylor expansion of the left side of this equation is equal to:

$U(S)=U(R)+(S-R) U^{\prime}(R)$

The Taylor expansion of the right side of equation (A.5) is equal to:

$(1-p(e)) U(R)+p(e) U(R)-p(e)\left[\int_{0}^{1} L(1+R) f(L) d L\right] U^{\prime}(R)+p(e)\left[\int_{0}^{1} L^{2}(1+R)^{2} f(L) d L\right] \frac{U^{\prime \prime}}{2}$ 
Equalizing these two equations yields the following:

$S=R-p(e)(1+R) \int_{0}^{1} L f(L) d L+\frac{1}{2} p(e) \frac{U^{\prime \prime}(R)}{U^{\prime}(R)} \int_{0}^{1} L^{2}(1+R)^{2} f(L) d(L)$

Where the risk premium $=-\frac{1}{2} p(e) \frac{U^{\prime \prime}(R)}{U^{\prime}(R)} \int_{0}^{1} L^{2}(1+R)^{2} f(L) d L$

Under risk aversion, the risk premium is positive because $p(e)>0, U^{\prime \prime}(R)<0, U^{\prime}(R)>0$. Therefore, we can conclude that R-S is larger than the expected loss. The expected return of originator is then equal to:

$1+S=\left[1-p(e) \int_{0}^{1} L f(L) d L\right](1+R)+\frac{1}{2} p(e) \frac{U^{\prime \prime}(R)}{U^{\prime}(R)} \int_{0}^{1} L^{2}(1+R)^{2} f(L) d(L)$ 


\section{References}

Berndt, A., and A. Gupta, 2009, Moral hazard and adverse selection in the originate-to-distribute model of bank credit, Journal of Monetary Economics 56, 725-743.

Brunnermeier, M.K., 2009, Deciphering the liquidity and credit crunch 2007-08, Journal of Economic Perspectives 23, 77100.

Citigroup, United States, Fixed Incomes, Strategy \& Analysis, Securitized Products Strategy (December 12, 2008): "Does the world need securitization? Yes, and six actions to restart the market".

Coval, J., J. Jurek, and E. Stafford, 2009, The economics of structured finance, Journal of Economic Perspectives 23, 3-25.

DeMarzo, P.M., 2005, The pooling and tranching of securities: A model of informed intermediation, Review of Financial Studies 18, 1-35.

Donnelly, C., and P. Embrechts, 2010, The devil is in the tails: Actuarial mathematics and the subprime mortgage crisis, Astin Bulletin 40, 1-33.

European Parliament, "Report on the proposal for a directive of the European Parliament and of the Council amending Directives 2006/48/EC and 2006/49/EC," Session document A6-0139/2009, March, 2009.

Fender, I., and J. Mitchell, 2009a, The future of securitisation: How to align incentives? BIS Quarterly Review 27-43.

Fender, I., and J. Mitchell, 2009b. Incentives and tranche retention in securitisation: A screening model (Centre for Economic Policy Research).

Gorton, G.B., and G.G Pennacchi, 1995, Banks and loan sales: marketing non-marketable assets, Journal of Monetary Economics 35(3): 389-411.

IOSCO, "Unregulated financial markets and products," Consultation report, May 2009.

Kendall, L.T., and M.J. Fishman, 2000. A primer on securitization (the MIT press).

Keys, B.J., T. Mukherjee, A. Seru, and V. Vig, 2011, 620 FICO, Take II: Securitization and screening in the subprime mortgage market, mimeo.

Keys, B.J., T. Mukherjee, A. Seru, and V. Vig, 2010, Did securitization lead to lax screening? Evidence from subprime loans, Quarterly Journal of Economics 125, 307-362.

Mian, A., and A. Sufi, 2009, The consequences of mortgage credit expansion: Evidence from the us mortgage default crisis, The Quarterly Journal of Economics 124, 1449.

Parlour, C.A., and G. Plantin, 2008, Loan sales and relationship banking, Journal of Finance 63, 1291-1314.

Rajan, U., 2010, The failure of models that predict failure: Distance, incentives and defaults, (London Business School).

Selody, J., and E. Woodman, 2009, Reform of securitization, Financial System Review 47-52.

U.S Department of the Treasury, "Monthly statement of the public debt of the United States: January 31, 2011."

US Treasury, "Financial regulatory reform: a new foundation," June, 2009.

Winter, R. A., 2000, Optimal knsurance under moral hazard, in: G.Dionne, ed., Handbook of Insurance (Boston: Kluwer Academic Publishers) , pp. 155-183. 